ARTIGO

do 10.22481/praxisedu.v15i33.5301

\title{
ECOLINGUÍSTICA: UMA BOA PRÁTICA DE EDUCAÇÃO AMBIENTAL PARA O AMBIENTE VIVIDO NA AMAZÔNIA AMAPAENSE
}

\author{
ECOLOGY IN THE LIVING ENVIRONMENT: POSSIBILITY FOR ENVIRONMENTAL \\ PRESERVATION IN THE AMAPANEAN AMAZON
}

\section{LA ECOLINGUÍSTICA EN EL MEDIO AMBIENTE VIVIDO: POSIBILIDAD PARA LA PRESERVACIÓN AMBIENTAL EN AMAZONIA AMAPAENSE}

\author{
Marcelo Conceição da Rocha Campos \\ Universidade Federal do Amapá - Brasil \\ Eliana do Socorro de Brito Paixão \\ Universidade Federal do Amapá - Brasil
}

\begin{abstract}
Resumo: Este trabalho derivou da pesquisa inicial para dissertação de mestrado e objetiva discutir a Ecolinguística como uma boa prática para educação ambiental, no Igarapé da Fortaleza-AP, com foco nas questões socioambientais existentes, associada à institucionalização de uma Área de Proteção Ambiental no local. O Igarapé da Fortaleza integra a Amazônia Setentrional Amapaense e se situa na divisa entre os municípios de Macapá e Santana. A urbanização do local foi impulsionada, inicialmente, pelo advento de grandes empreendimentos privados para exploração de minério e madeira, induzindo um fluxo populacional que se instalou no local sem os padrões vigentes de urbanização e ordenamento territorial, sem infraestrutura adequada e em situação de risco iminente, devido à degradação ambiental e vulnerabilidade social. Além disso, o poder público criou uma Área de Proteção Ambiental no local, com a intenção de regular as práticas ecológicas sem considerar as questões socioambientais. Na prática, não alcança os resultados esperados, pois, na verdade, apenas camufla interesses. Esse contexto inspirou a pesquisa, a qual teve abordagem qualitativa, sendo de natureza bibliográfica e os dados tratados sob a inspiração na análise de conteúdo. Um dos principais resultados revelou que para a educação ambiental, em um ambiente vivido inóspito como o Igarapé da Fortaleza-AP, é possível utilizar como recurso pedagógico a Ecolinguística, em função de estreita relação entre linguagem e meio ambiente de forma acessível à sociedade.
\end{abstract}

Palavras-chave: Questões socioambientais no ambiente vivido e preservação; Ecolinguística; Educação Ambiental.

\begin{abstract}
This work was derived from the initial research for a master's thesis and aims to discuss Ecolinguistics as a good practice for environmental education, in the Igarapé of Fortaleza (Amapa), focusing on existing socio-environmental issues, associated to the institutionalisation of an Environmental Protection Area in the area. The Igarapé da Fortaleza integrates the Northern Amazon of Amapa and is located in the border between the municipalities of Macapá and Santana. The site's urbanisation was initially driven by the advent of large private enterprises for the exploration of ore and timber, inducing a population flow that was installed in the locality without the current standards of urbanisation and territorial planning, inadequate infrastructure and in an imminent risk situation due to environmental degradation and social vulnerability. Besides, public authorities created an Environmental Protection Area in the same area, with the intention of regulating ecological practices
\end{abstract}


without considering socio-environmental issues. In practice, they do not achieve the expected results, because, in fact, they only camouflage interests. This context inspired the research, which had a qualitative approach, being of a bibliographic nature. The data was managed according to content analysis references. One of the main results revealed that for environmental education, in an inhospitable environment such as the Igarapé of Fortaleza, it is possible to use Ecolinguistics as a pedagogical resource, due to the close relationship between language and environment in a way accessible to society.

Keywords: Socioenvironmental issues in the lived environment and preservation; Ecolinguistics; Environmental education.

Resumen: Este trabajo derivó de la investigación inicial para disertación de maestría y objetiva discutir la Ecolinguística como una buena práctica para educación ambiental, en el Igarapé de la Fortaleza (Amapá), con foco en las cuestiones socioambientales existentes, asociada a la institucionalización de un Área de Protección Ambiental en el local. El Igarapé de la Fortaleza integra la Amazonia Septentrional Amapaense y se sitúa en la frontera entre los municipios de Macapá y Santana. La urbanización del local fue impulsada inicialmente por el advenimiento de grandes emprendimientos privados para explotación de mineral y madera, induciendo un flujo poblacional que se instaló en el local sin los patrones vigentes de urbanización y ordenamiento territorial, sin infraestructura adecuada y en situación de riesgo inminente debido a la degradación ambiental y la vulnerabilidad social. Además, el poder público creó un Área de Protección Ambiental en el lugar, con la intención de regular las prácticas ecológicas sin considerar las cuestiones socioambientales. En la práctica, no alcanzan los resultados esperados, pues, en realidad, sólo camuflan intereses. Este contexto inspiró la investigación, la cual tuvo abordaje calitativo, siendo de naturaleza bibliográfica y los datos tratados bajo la inspiración en el análisis de contenido. Uno de los principales resultados reveló que para la educación ambiental, en un ambiente vivido inospito como el Igarapé de la Fortaleza, es posible utilizar como recurso pedagógico a Ecolinguística, en función de estrecha relación entre lenguaje y medio ambiente de forma accesible a la sociedad.

Palabras llave: Cuestiones socioambientales en el ambiente vivido y preservación; ecolinguiística; Educación ambiental.

\section{INTRODUÇÃO}

O elevado crescimento das atividades industriais no mundo, a partir da década de 1960, do século XX, suscitou o surgimento de movimentos ambientalistas que questionavam os impactos ambientais decorrentes. Historicamente, há relatos de que diversos eventos foram realizados com esse fim; durante alguns deles, surge a educação ambiental e a depuração dessa vertente da educação. Essa ação ainda permanece, assim como outros movimentos e entidades foram criados para fortalecer as discussões e, ao mesmo tempo, promover ações, planos para minoração das questões ambientais emergidas, além de projetos de sensibilização e conscientização sobre o assunto. $\mathrm{Na}$ esfera governamental, erigiu-se toda uma estrutura organizacional destinada não só à regulação, mas também à legislação e controle das questões ligadas ao meio ambiente. 
Trata-se de uma preocupação que não surgiu à toa. Os meios de comunicação relatam, constantemente, as mazelas ambientais que afligem o mundo: paisagens destruídas, a extinção de diversas espécies vegetais e animais, catástrofes climáticas, dentre outras. Resta, então, imperativa a criação de alternativas e a tomada de atitude para que as comunidades possam interagir com a natureza de maneira menos destrutiva, assumindo uma postura ambientalista e abandonando práticas de degradação dos recursos naturais e de insalubridade ambiental.

Nos dias atuais, a preocupação com a destruição do meio ambiente é global. Em razão disso, tem-se a relevância da análise do ambiente vivido no Igarapé da Fortaleza-AP, situado na região sudeste do estado do Amapá, que integra a Amazônia Setentrional brasileira, entre os municípios de Macapá e de Santana; utilizando como viés pedagógico a Ecolinguística, a qual se apresenta como um caminho alternativo, uma nova perspectiva que o homem assume diante do mundo através da formação de um discurso sólido em defesa do meio ambiente.

Dessa forma, a partir de uma pesquisa bibliográfica, com abordagem qualitativa, amparados em Minayo (2002) e da análise de conteúdo pautada em Bardin (2011), este artigo apresenta um caminho para a minoração de questões socioambientais e preservação do ambiente vivido no Igarapé da Fortaleza-AP; uma possibilidade para a prática da educação ambiental no local, sob o viés da Ecolinguística, a fim de que homens e mulheres estabeleçam uma nova dinâmica de relação com o seu ambiente. Objetiva, portanto, discutir a Ecolinguística como uma boa prática para educação ambiental, no Igarapé da Fortaleza-AP, com foco nas questões socioambientais existentes, associado à institucionalização de uma Área de Proteção Ambiental no local.

Este artigo apresenta a seguinte configuração: além desta parte introdutória, nas seções subsequentes, discute-se o Igarapé da Fortaleza como integrante da Amazônia Amapaense e suas questões socioambientais; a Ecolinguística na contextualização de conceitos e o seu diálogo com a educação ambiental; e a Ecolinguística como uma possibilidade de boa prática para educação ambiental.

A relevância do conteúdo abordado neste artigo situa-se no campo social, político e acadêmico, em todos eles, o foco está no incentivo ao debate, a reflexões e elaboração de práticas, com o suporte na Ecolinguística, que se derivem da problematização das questões socioambientais, a fim de que a comunidade do Igarapé da Fortaleza-AP possa compreender o 
ambiente vivido e desenvolver atitudes que transformem o seu próprio comportamento e dos gestores públicos.

\section{AMAZÔNIA AMAPAENSE: O IGARAPÉ DA FORTALEZA E SUAS QUESTÕES SOCIOAMBIENTAIS}

O Estado do Amapá, no qual está inserido o Igarapé da Fortaleza, possui cerca de 73\% de seu território em áreas protegidas (Unidades de Conservação e Terras Indígenas), sendo o Estado com maior porcentagem de áreas, nessa configuração, no Brasil, fato que é reconhecido pelo Ministério do Meio Ambiente - MMA (AMAPÁ, 2012). Este Estado integra a faixa de terras que compõem a Amazônia Setentrional, a qual apresenta diversas particularidades: está localizada, em grande parte, no hemisfério norte; possui vastas áreas florestadas ainda bem conservadas ou transformadas em grandes unidades de proteção ambiental ou reservas indígenas; possui baixa densidade demográfica; apresenta rede urbana constituída por pequenas cidades; e grande parte de seu território compõe a faixa de fronteira ${ }^{1}$ internacional (SANTOS, 2012), por limitar-se com a Guiana Francesa e Suriname.

A despeito dessas particularidades, os processos de gestão das áreas sob proteção legal $^{2}$ são ineficientes, muito vulneráveis e com poucos insumos disponíveis, dificuldades que impedem seu desempenho (AMAPÁ, 2012). Nesse cenário, encontra-se o Igarapé da Fortaleza/AP, o qual apresenta um aspecto sui generis: está situado, na divisa entre os municípios de Macapá e Santana, sendo que na margem esquerda, vinculada ao município de Macapá, tem-se uma Área de Proteção Ambiental - APA com 2.063 habitantes; na outra margem, no município de Santana, há uma área reconhecidamente urbana com 4.122 habitantes, denominada de bairro Fortaleza. Trata-se de aglomerado subnormal ${ }^{3}$ que se formou às margens de um rio de mesma denominação, cuja conexão se dá por uma rodovia que atravessa o igarapé.

O trajeto para se chegar a esse aglomerado pode ser realizado tanto por via terrestre, quanto por via fluvial. Por via terrestre pode ser feito por meio das rodovias AP-010 e AP-

\footnotetext{
${ }^{1}$ A Faixa de Fronteira, segundo a atual Constituição (BRASIL, 1988), tem uma extensão de até $150 \mathrm{~km}$, e é considerada basilar para defesa do território nacional. A sua ocupação e utilização estão reguladas pela Lei n. ${ }^{\circ} 6$. 634, de 2 de maio de 1979 e Decreto n. ${ }^{\circ} 85.064 / 1980$.

2 O Estado do Amapá possui cerca de $73 \%$ de seu território em áreas protegidas (Unidades de Conservação e Terras Indígenas), sendo o Estado com maior porcentagem de áreas protegidas do Brasil (fato também reconhecido pelo Ministério do Meio Ambiente - MMA) (AMAPÁ, 2012).

${ }^{3}$ Aglomerado subnormal, segundo o IBGE (2010), é um conjunto de, no mínimo, 51 unidades habitacionais erguidas em terreno de propriedade alheia - seja pública ou particular - dispostas, geralmente, de maneira desordenada, sendo carentes de serviços públicos essenciais.
} 
070, que são responsáveis pela ligação entre os municípios de Macapá e Santana; ao passo que pela via fluvial, o acesso pode ser realizado por meio do Igarapé da Fortaleza, que também é uma saída para o Rio Amazonas (AGUIAR, 2003). Pelo fato de apresentar uma extensão avultada, o Igarapé da Fortaleza pode ser utilizado também para a navegação (TAKIYAMA, 2003), possibilitando a entrada de barcos e balsas provenientes de diversas localidades do próprio Estado, bem como das regiões ribeirinhas do Estado do Pará, apresentando-se como rota estratégica para a circulação de pessoas e comercialização de mercadorias.

De acordo com IBGE (2010), grande parte da população local é oriunda das ilhas ribeirinhas do vizinho Estado do Pará, que migrou para o Amapá, sobretudo, intentando novas oportunidades, a fim de conseguir melhorias na qualidade de vida. A atividade econômica dos moradores que até 1995 se restringia, basicamente, ao extrativismo, à pesca, ao comércio e aos estaleiros; passou a apresentar, a partir dos anos de 2000, relação com os setores primário (pesca artesanal, pecuária bovina), secundário (pequenas olarias) e terciário, com a venda de gêneros alimentícios, além da comercialização em bares e restaurantes (CUNHA et, 2003).

O Igarapé da Fortaleza-AP é interligado por inúmeras ressacas - ecossistema ${ }^{4}$ típico da zona costeira do Amapá -, tanto do município de Macapá quanto do município de Santana, e é justamente nessas áreas que se observa uma intensa ocupação urbana desorganizada, tanto por habitações como por instalações de atividades, culminando em um ambiente com notório desequilíbrio ambiental, o que resulta na redução de biodiversidade e qualidade de vida, sobretudo devido à produção de resíduos poluentes.

Os dados postos possibilitam afirmar que no Igarapé da Fortaleza se estabeleceu uma enorme contradição. Em que pese faça parte de uma área de preservação ambiental, a antropização com elevada degradação é acentuada, as construções não atendem aos padrões de urbanização e ordenamento territorial, apresentando alinhamento irregular e vias de circulação estreitas. A degradação assinalada, interfere na qualidade de vida dos moradores, na medida em que vivem em condições insalubres, devido à qualidade da água consumida, na forma de acondicionamento do lixo e na ausência de esgotamento sanitário. Estas questões estão naturalizadas no cotidiano dos moradores, de tal modo que não questionam essa condição de vivência. O aparelho estatal, por seu turno, não se faz tão presente nessa realidade, mesmo tendo a responsabilidade pela preservação ambiental no local. Ademais, há

\footnotetext{
${ }^{4}$ É o conjunto formado pelos seres vivos e seu meio ambiente, considerados como um todo, e suas interrelações" (COUTO, 2009, p. 17).
} 
um conflito no cumprimento de funções entre as duas esferas de governos municipais em relação à formulação e execução de políticas públicas consistentes e demandadas socialmente (BONETI, 2006).

Cabe destacar, que o processo de ocupação das áreas de ressaca do Igarapé da Fortaleza-AP foi motivado sobremaneira pelo advento de grandes empreendimentos privados para exploração de minério e madeira em regiões próximas, além da exploração de atividades ligadas ao extrativismo mineral, na medida em que olarias retiram argila de suas áreas de várzea e de ressacas para a fabricação de tijolos e de telhas (FIGUEIRA, 2013), práticas econômicas que favoreceram a ampliação do adensamento populacional.

É possível observar a degradação produzida pelo descarte de lixo e esgoto a céu aberto, poluição das águas, aumento de animais roedores e resíduos poluentes, além da existência de fossas a céu aberto, que contribuem para a poluição do igarapé e do próprio lençol freático. Embora haja a coleta pública no local, observa-se também a contaminação gerada pelo descarte inadequado de resíduos sólidos, que se espalham sob as passarelas, nos quintais e dentro do igarapé, contaminando o ecossistema do aglomerado. Os moradores asseveram que não jogam lixo no leito do igarapé, mas não é essa a situação observada.

O manifesto desequilíbrio ambiental aponta, segundo Lefebvre (2006) para aquele ambiente vivido, a subtração do direito à cidade dos moradores, relacionados ao direito à liberdade, ao habitat, ao próprio habitar, o direito à obra, à apropriação de garantias legais. Daí a necessidade de se pensar a prática de uma educação ambiental que ajude os moradores a olharem criticamente o seu contexto de vivência de maneira a desenvolverem a consciência crítica (FREIRE, 1981), a refletirem sobre a situação em que vivem e a necessidade de recuperação e preservação ambiental, considerando a institucionalização da APA no local. Nessa direção, o uso da Ecolinguística para a educação ambiental pode ser uma boa prática.

\section{A ECOLINGUÍSTICA NA CONTEXTUALIZAÇÃO DE CONCEITOS}

Quando se busca ler sobre a literatura fundamental acerca da Ecolinguística, um dos primeiros nomes que se encontra é o de um brasileiro, chamado Francisco Gomes de Matos, que foi um dos pioneiros, dentre os linguistas brasileiros, a se interessar pelo tema. Sua notoriedade nesse campo é tão destacada que é possível ver seu nome no início do famoso ensaio de Michael Halliday, intitulado "New ways of meaning: the challenge to Applied 
Linguistics", o qual foi lido no IX Congresso Mundial de Linguística Aplicada, na cidade de Thessaloniki, na Grécia (COUTO et al., 2017).

Segundo Sarmento (2004), a origem da Ecolinguística remonta a década de 1970, quando Einar Haugen publica a obra "A Ecologia da Língua”, na Stanford University Press, sugerindo tratá-la como um fenômeno ecológico, abordando-a como interações entre qualquer língua e o meio ambiente. Há que se salientar, contudo, que existem autores que remetem o surgimento da Ecolinguística para um período anterior a essa década (1959), por exemplo, a Sapir e Whorf ou a John Trim.

Couto (2009, p. 19) afirma que Ecolinguística é “o estudo das relações entre língua e meio ambiente". O próprio prefixo "eco" já denota que ela se insere no plano da Ecologia. Canto e Fernandes (2013, p. 203) ampliam esse entendimento dizendo:

[...] pensamos no prefixo eco- de Ecolinguística como um meio ambiente em que tudo se relaciona, com isso temos uma inter-relação entre seres humanos e natureza (os seres bióticos e os abióticos), aliados à concepção de linguística, em seu sentido amplo, como sendo o estudo da linguagem. Temos, dessa forma, a Ecolinguística, uma nova maneira de ver, de estudar os fenômenos da linguagem.

A sua base teórica está centrada numa visão dinâmica da língua, isto é, sugere o estudo das inter-relações entre língua, indivíduos e meio ambiente a partir do entrelaçamento de conhecimentos provenientes das ciências da linguagem e da ecologia. Esse aspecto integrador parte do princípio de que a língua é um sistema que também mantém inter-relação com outros elementos do ecossistema do qual faz parte.

Alguns conceitos de ecossistema, a exemplo de meio ambiente (MA), habitat e nicho, possuem termos equivalentes em Ecolinguística. $\mathrm{O}$ ecossistema biológico, por exemplo, corresponde ao ecossistema linguístico, formado por três elementos (Figura 1): povo/população $(\mathrm{P})$, que vive em certo lugar/território $(\mathrm{T})$; e que se comunica por meio de uma língua (L). A junção desses três elementos forma o chamado Ecossistema Fundamental da Língua (EFL), que se desdobra em, pelo menos, três meio ambientes menores: o MA social, o MA mental e o MA natural (COUTO, 2009).

Figura 1 - Ecossistema Fundamental da Língua (EFL). 


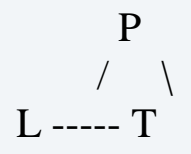

Fonte: Adaptado de COUTO, 2007, p. 91.

O MA social se refere aos membros do povo/população, à forma como eles se organizam socialmente. Já o MA mental, faz referência à relação entre língua e suas interrelações com o cérebro/mente ou com as redes de conexões neurais. Por sua vez, o MA natural é constituído por $\mathrm{L}$ em relação a $\mathrm{T}$ e os membros de $\mathrm{P}$, isto é, o meio ambiente natural da língua é o próprio mundo físico, uma vez que toda língua é falada por um povo que vive e convive em um local (território).

Importantes conceitos ligados às disciplinas ambientais são discutidos pela Ecolinguística, com a finalidade de ampliar a compreensão e aguçar o debate relativo à temática ambiental. Dentre esses, pode-se citar o de Ecologia, que é "o estudo das interrelações entre os seres vivos e entre eles e seu meio ambiente" (COUTO, 2009, p. 17). Existe uma variedade de conceitos da Ecologia relevantes para o debate, a exemplo de diversidade, que tem a ver com a multiplicidade de espécies que se inter-relacionam num ecossistema; holismo, que diz respeito ao fato de o investigador delimitar um ecossistema e estudá-lo em sua totalidade; inter-relações, que são as interações que ocorrem dentro do ecossistema; e adaptação, que se refere às modificações feitas para a sobrevivência das espécies no ecossistema (COUTO, 2009).

A Ecolinguística toma como base a ecologia biológica para estruturar seus alicerces epistemológicos e averiguar de que forma a linguística analisa elementos ligados à seara ambiental, representando uma adesão da linguagem ao movimento ecológico, no sentido de sugerir meios para contribuir com uma educação ambiental que convença as novas gerações sobre os perigos de se degradar o ecossistema (SILVA, 2010).

A visão ecológica de mundo comungada pela Ecolinguística impõe, principalmente, uma mudança de postura. Há a necessidade de transformar a forma de ver o mundo, de mudar o foco, considerando que:

para se praticar Ecolinguística e qualquer uma de suas ramificações, é necessário mudar. Do contrário, seríamos pseudoecolinguistas. Para ser um bom ecolinguista, ninguém precisa deixar o que fazia antes. Se era um fonólogo, pode continuar a fazer fonologia, além da Ecolinguística, mesmo usando metodologias cartesiano-newtonianas, embora hoje em dia haja 
modelos fonológicos com muitas afinidades com a visão ecológica de mundo [...] (COUTO; COUTO, 2016, p. 398).

Assim, o fortalecimento dos valores ambientais saudáveis passa também pelo revigoramento do indivíduo como ser informado e educado, municiado dos instrumentos cognitivos que o torne capaz de saber e exercer seus direitos, de agir, de romper com o discurso dominante que atribui ao "outro" a causa das mazelas ambientais, de maneira que:

analisar as polifonias que atuam na criação de novos conceitos, revelar e entender as ideologias motrizes que "permitem" que esse discurso seja propagado e quais seus interesses e objetivos são uma tarefa fascinante para o emergente campo da Ecolinguística (LESTINGE, 2013, p. 23-24).

Além da manifesta preocupação com o meio ambiente e ecossistema, a Ecolinguística volta sua atenção, de maneira relevante, para a língua, uma vez que ela é essencial e imprescindível no processo de engendramento de discursos que abordam questões ambientais. Dessa maneira, para Couto (2007, p. 46), “a Ecolinguística nos convida a encarar os fenômenos da linguagem do ponto de vista do respeito e da preservação da vida, em todas as suas manifestações".

Nessa esteira, Couto (2007) apresenta um conjunto de princípios, contidos no movimento chamado de ecologia profunda, proposto pelo filósofo Arne Naess, que podem, perfeitamente, servir de diretriz para uma educação com amparo nos pressupostos ecolinguísticos, a exemplo de que a riqueza e a diversidade das formas de vida contribuem para a realização de valores em si mesmos e os seres humanos não têm nenhum direito de reduzir essa riqueza e diversidade, exceto para satisfazer necessidades humanas vitais.

Além desses princípios, o referido autor menciona, dentre outros, que o bem-estar e o florescimento da vida humana e da não-humana sobre a terra têm valor em si próprios, e que a atual interferência humana no mundo não-humano é excessiva e a situação está piorando aceleradamente. Ademais, aponta que as políticas precisam ser mudadas e que aqueles que subscrevem os princípios precedentes têm a obrigação de tentar implementar, direta ou indiretamente, as mudanças necessárias.

A Ecolinguística apresenta algumas possibilidades de utilização. Sarmento (2004) menciona, entre outros, abordar a questão da ecologização das línguas e sua contribuição para as mentalidades; tratar a língua em face dos sistemas biológicos diversos e similares; elaborar textos, glossários, que abordem a relação entre língua e meio ambiente; discutir as questões 
sobre Ecolinguística e ensino; e ensinar ecoeducação, isto é, fomentar uma educação voltada às questões ecológicas, ou seja, educação ambiental com esse enfoque.

\section{DIÁLOGO ENTRE EDUCAÇÃO AMBIENTAL E ECOLINGUÍSTICA}

A educação ambiental surgiu como imperativo das grandes transformações ocorridas na sociedade moderna. Para compreender esse contexto no qual as agressões ao meio ambiente começam a reverter contra o homem todo mal cometido, em forma de desastres e catástrofes naturais, há necessidade de retornar à década de 1960, embora, segundo Figueiredo (2007, p.70), o ambiente à época, fosse visto "apenas como um componente a mais no processo pedagógico". Porém, foi nessa década que a emergência da EA no mundo começou a ser discutida.

Um dos condicionantes foi o elevado crescimento das atividades industriais nos países ricos a partir dos anos de 1960, de forma que a poluição causada pelas indústrias, em diversas partes do mundo, estava provocando uma rápida queda na qualidade de vida da população. Em 1962, a jornalista Rachel Carson lança o livro Silent Spring (Primavera Silenciosa), obra que se tornou clássica dos movimentos ambientalistas, na qual alertava sobre os efeitos nefastos da ação humana sobre o meio ambiente no mundo.

Segundo Figueiredo (2007), a queda brusca na qualidade vida suscitada pela degradação ambiental, motivou a Organização das Nações Unidas (ONU) a discutir essas questões em 1968, instigada pelo chamado oficial da delegação da Suécia sobre a necessidade de uma abordagem global relativa aos problemas ambientais.

Ainda em 1968, a UNESCO realiza um estudo sobre o meio ambiente e escola, junto a 79 países membros, destacando que o ambiente constitui-se em um conceito que envolve, também, aspectos sociais, políticos, econômicos, culturais e éticos, além dos já tradicionais físicos, químicos e biológicos (FIGUEIREDO, 2007).

A vulnerabilidade dos ambientes naturais coloca em xeque a sobrevivência da humanidade. Em razão dessa realidade, ocorreu, vertiginosamente, o crescimento dos movimentos ambientalistas e das preocupações ecológicas, tanto por parte dos governos, quanto pela iniciativa privada, através, principalmente, de ações de Organizações Não Governamentais (ONGs) ligadas à área ambiental.

Como exemplo desse processo de institucionalização da temática ambiental no plano governamental brasileiro, criou-se a Secretaria Especial do Meio Ambiente (Sema), 
subordinada à Presidência da República, em 1973; houve a institucionalização da Política Nacional de Meio Ambiente (PNMA), em 1981; a criação do Programa Nacional de Educação Ambiental (ProNEA) em 1990; a instituição da Política Nacional de Educação Ambiental (Lei 9795/99), relevantes instrumentos para a tutela do meio ambiente; e a Política Nacional de Resíduos Sólidos (PNRS) em 2010.

A propósito, a Lei 9795/99, artigo $1^{\circ}$, oferta a definição de educação ambiental.

Entendem-se por educação ambiental os processos por meio dos quais o indivíduo e a coletividade constroem valores sociais, conhecimentos, habilidades, atitudes e competências voltadas para a conservação do meio ambiente, bem de uso comum do povo, essencial à sadia qualidade de vida e sua sustentabilidade.

Inconteste, então, é a necessidade de que a educação forneça às pessoas condições para o desenvolvimento de aptidões que lhes possibilite atuar de forma proativa nas questões ambientais, tanto no uso quanto no gerenciamento dos recursos naturais. Contudo, a educação ambiental tem sido uma expressão largamente usada em textos de políticas e programas de educação, de modo que isso pode cooperar para uma apreensão ingênua da ideia que, de fato, a terminologia busca externar.

Carvalho (2012) salienta que o termo "educação ambiental" passou a ser empregado como tudo aquilo que pode ser agrupado no conjunto de "boas práticas ambientais" ou "bons comportamentos ambientais", de forma que essa ideia de espaço de convergência de boas intenções ambientais tenta sugerir que somente respeitar a natureza seria premissa suficiente para intervir na atual crise ecológica, tentando silenciar a complexidade que há em torno dos diferentes modos de acesso aos bens ambientais e uso desses bens.

Freire (1981) alerta para os riscos que uma compreensão simplista, superficial de um tema poderia causar e conduzir à consciência ingênua, a qual, segundo ele, "revela uma certa simplicidade, tendendo a um simplismo na interpretação dos problemas, [...]. Suas conclusões são apressadas, superficiais" (FREIRE, 1981, p. 40). Ora, é possível que a superação dessa consciência ingênua, proveniente das condições de exclusão e opressão que bloqueiam a expressão plena da humanidade, ocorra "[...] quando nos defrontamos, coletivamente, com a necessidade de agir sobre o real que nos rodeia para transformá-lo" (PERNAMBUCO; SILVA, 2006, p. 211).

Concordando com esses autores, entende-se que para agir sobre a realidade instaurada, como no ambiente vivido no Igarapé da Fortaleza-AP, é preciso o envolvimento 
dos moradores, os quais podem desempenhar um papel fundamental na proteção do meio ambiente e na minoração das questões que permeiam o seu contexto de vivência, já que conhecem o local em que habitam. Como suporte nesse processo, sugestiona-se o uso da Ecolinguística, para subsidiar alternativas viáveis e fomentar a tomada de ações, pela própria comunidade, para que haja uma interação com a natureza de forma mais consciente e menos destrutiva.

Couto (2007) afirma que a Ecolinguística é importante porque representa uma nova postura que o linguista poderá adotar por meio da formação de um discurso consistente em prol do meio ambiente. Um discurso que possibilite o conhecimento ambiental e, posteriormente, a consciência ambiental. Logo, essa disciplina pode ser um instrumento útil para a ampliação das reflexões que tratam da temática ambiental e um passo rumo à educação de cidadãos mais comprometidos com o ecossistema.

Além da preocupação com o meio ambiente e o ecossistema, a Ecolinguística favorece o interesse e atenção pela língua, uma vez que ela também é parte indispensável na construção de discursos que contemplam temáticas ambientalistas. Segundo Couto (2007, p. 46), "a Ecolinguística nos convida a encarar os fenômenos da linguagem do ponto de vista do respeito e da preservação da vida, em todas as suas manifestações”. Há que se considerar, também, o caráter político que a Ecolinguística pode desempenhar em face da atual crise ecológica, na tentativa de revelar o que subjaz o discurso daqueles que destroem o meio ambiente, com a mentalidade desenvolvimentista, visando tão somente ao lucro, aquilo que a natureza pode oferecer em termos econômicos.

\section{ECOLINGUÍSTICA E EDUCAÇÃO AMBIENTAL NO IGARAPÉ DA FORTALEZA- AP: UMA POSSIBILIDADE DE BOA PRÁTICA PARA PRESERVAÇÃO AMBIENTAL}

As questões socioambientais em comunidades amazônicas apresentam forte semelhança no que diz respeito às formas de ocupação e seus indutores, como também das características relacionadas ao ambiente natural com grandes áreas de florestas. Se por um lado é necessária a preservação para o bem da humanidade, as riquezas contidas nas florestas e no solo são atrativas para o grande capital, que num empenho perverso de apropriação não considera os impactos sociais e ambientais que podem ser engendrados. 
Como já anunciado, o processo de ocupação do Igarapé da Fortaleza se intensificou a partir da instalação de grandes empreendimentos privados no município de Santana, que foram incentivados pelos planos e programas desenvolvimentistas hegemônicos pensados para o Estado do Amapá, como, por exemplo, às hidrelétricas, madeireiras e mineradoras. Ao longo de anos, além da exploração dos recursos naturais ou da degradação ambiental, foram surgindo novas ocupações, aumento dos bolsões de pobreza e o distanciamento com o compromisso social, o que nutre a depreciação da qualidade socioambiental. Como adverte Figueiredo (2007, p. 67), “a ação do ser humano sobre a natureza é de dominação, levando a uma dicotomia, que fragmenta a realidade em um mundo humano e mundo natural. [...]. Em nosso cotidiano, pode-se identificar a crise nas consequências sociais [..]”"

O quadro posto sobre o Igarapé da Fortaleza foi determinante para destacar a existência de um paradoxo no local. Criou-se uma APA, como vitrine política de governo, construída sob a suposta preocupação com a proteção da biodiversidade, mas as questões socioambientais com feições urbanas permanecem sem a devida atenção, estabelecendo-se um contraste visual e vivencial. É como se as ideias estivessem fora do lugar (MARICATO, 2001). Ao mesmo tempo em que se pensou na preservação da cobertura vegetal, não foram considerados os problemas locais, relacionados à moradia e ao saneamento ambiental, elementos esses fundamentais na definição de um ambiente salubre ou não.

Esse cenário de ocupação ilegal e desordenada, em áreas não recomendadas para habitabilidade, visivelmente insalubres, fora do controle do ente estatal, em condições precárias e de forma desregrada, com inchaço populacional progredindo ao longo do tempo e estimulado pelo advento de pessoas atraídas pelo grande capital, como é a realidade do ambiente abordado, amolda-se à categoria de "cidade ilegal”, cunhada por Maricato (2001). Diante da informalidade do surgimento desses núcleos urbanos, resta aos moradores conviverem sem ter reconhecido o seu direito à cidade, na perspectiva defendida por Lefebvre (2006) e abandonadas pelo Poder Público (ALVES, 2006).

As diligências iniciais realizadas no local permitiram perceber que a ausência do poder público é notória, que pode ser ratificada pela demora na solução dos problemas que se aguçam e na precária oferta de serviços públicos essenciais, deixando a população sem respostas rápidas às suas necessidades, o que revela o elevado grau de vulnerabilidade social e ambiental destas áreas hiperperiféricas e de fronteira urbana (TORRES, 2000).

A mobilidade nas passarelas utilizadas pelos moradores para o trânsito no local está comprometida pelo estado deplorável em que elas se encontram: quase intransitáveis. Quanto 
ao acesso aos serviços públicos, a comunidade não dispõe de uma delegacia dentro do local, afetando a questão da segurança; não existe também Unidade Básica de Saúde (UBS), comprometendo a vida daqueles que procuram atendimentos médicos; ademais, esse cenário atenta contra os direitos e garantias fundamentais insculpidos na Constituição da República de 1988.

Frente à degradação crescente do meio ambiente, inclusive ameaçando a vida de maneira perversa, é urgente uma reação da sociedade no sentido de preservar natureza e equacionar as questões socioambientais existentes. Cada indivíduo deve assumir uma postura reflexiva, visando a buscar alternativas para a minoração das questões assinaladas. Assim, uma maneira de ingressar nessa luta é aderir aos postulados da ecologia assimilados pela Ecolinguística (COUTO, 2009), num processo pedagógico que estimule os integrantes da comunidade a realizarem uma leitura crítica da realidade local.

É através da linguagem e de leituras aprofundadas que o indivíduo adquire competência e capacidade para formular discursos consistentes, e que servirão como instrumento de estímulo à reflexão para o despertar intrínseco da consciência do sujeito. Esse processo de linguagem e leitura se faz imprescindível na formação de cidadãos comprometidos com a causa ambiental, no processo de educação e consciência sobre uma vida mais sustentável (SILVA, 2010, p. 2).

Como possibilidade paliativa, é importante criar espaços coletivos para educação ambiental, visando aprendizagem e potencializar o uso de recursos alternativos. Além de realizar palestras, debates, reuniões com a comunidade sobre a destinação dos resíduos sólidos, acerca do reaproveitamento do lixo orgânico, de propor a ampliação do número de lixeiras, de trabalhar a reciclagem, de desestimular a derrubada de árvores e a contaminação do igarapé, é preciso buscar continuamente outras alternativas.

Reigota (2002) afirma, que a tendência da educação ambiental é ir além de uma prática educativa e se consolidar como uma filosofia de educação presente em todas as disciplinas, possibilitando uma visão mais ampla do papel da escola no cenário ecológico local e planetário.

Sob o prisma da educação ambiental, a Ecolinguística apresenta, diversas alternativas, como exposto anteriormente, para auxiliar as escolas na tarefa de sensibilização para mudança na mentalidade e na atitude das pessoas, seguindo as orientações dos Parâmetros Curriculares Nacionais (PCN) e da Política Nacional de Educação Ambiental, que dispõem sobre a inserção da educação ambiental no ensino formal. Logo, uma educação 
ambiental, sob o viés da Ecolinguística, poderá "contribuir para uma mudança de valores e atitudes, formando um sujeito ecológico capaz de identificar e problematizar as questões socioambientais e agir sobre elas" (CARVALHO, 2012, p. 158).

A minoração da realidade diagnosticada no local deverá envolver aspectos diversos e a participação das diferentes instâncias da sociedade, sendo relevante modificar a relação da comunidade com os elementos do meio ambiente, fortalecendo a ideia de pertença, a fim de poder avançar na luta pela melhoria ambiental e da qualidade de vida.

as lutas populares emancipatórias podem ser elementos-chave na construção de uma cidadania ambiental, estabelecendo um campo de diálogo entre reivindicações ambientais e as demandas populares. Essa imbricação é o que torna possível tanto maior visibilidade e legitimação dos valores ambientais no conjunto da sociedade quanto um enraizamento popular da luta ecológica enquanto luta cidadã (CARVALHO, 2012, p. 170-171).

Há a necessidade, portanto, de buscar a manutenção harmônica das interações entre os seres vivos e fazer delas a questão principal de toda e qualquer prática, transcendendo qualquer posição que vá ao encontro da manutenção do sistema capitalista e das mazelas a ele referentes. Além disso, a Ecolinguística "traz uma visão de luta pelas vias da resistência, da mudança gradual de mentalidade, da transformação contínua e em longo prazo que possa levar à concepção da vida como lastro para moralidade", conforme assinala Couto et al (2017, p. 100-101).

Desse modo, no decurso das análises, foi possível depreender que a Ecolinguística tem relação direta com o processo de educação ambiental e que poderá ser utilizada como uma boa prática para mudança da realidade vivenciada no Igarapé da Fortaleza-AP. Pode, também, colaborar com a construção de uma visão sustentável para adoção de práticas ecologicamente corretas, a partir da problematização do ambiente vivido (LEFEBVRE, 2006), auxiliando os moradores no desenvolvimento de conscientização, nos moldes defendidos por Freire (1981), para o fomento de um ambiente equilibrado e progressiva proteção ambiental.

\section{CONSIDERAÇÕES FINAIS}

As questões relatadas, materializadas no Igarapé da Fortaleza, não são específicas do Estado do Amapá, mas em grande parte da Região Amazônica, em função das históricas incursões capitalistas. Os desafios ligados às questões socioambientais são prementes, de 
modo que urge a necessidade de um processo educacional que promova o desenvolvimento de práticas ambientais comprometidas com a qualidade de vida, tratando das questões socioambientais de maneira crítica, contextualizada e globalizante.

Resta, então, irrefutável o argumento de que a Ecolinguística se apresenta como uma relevante ferramenta para a propagação de saberes, reflexões que tenham como centro das atenções a questão ambiental e o fomento de práticas sustentáveis na comunidade em estudo, gerando, como consequência, avanços em direção ao progresso na educação de cidadãos para que se sintam, substancialmente, comprometidos com o meio ambiente. Esta disciplina, além de difundir o valor de se ponderar sobre a linguagem ao lado da biodiversidade, apresenta sugestões e alternativas para cooperar na busca de uma educação ambiental que possa persuadir a atual geração sobre os perigos de se depredar o meio ambiente e de demonstrar que a língua é parte do processo ambiental.

O contato inicial com a comunidade possibilitou depreender que há notável avidez pelo processo de transformação da situação ambiental adversa, naturalizada no Igarapé da Fortaleza-AP. Nesse sentido, a implementação dos princípios da Ecolinguística propõe o desenvolvimento de práticas educacionais que podem inspirar a população local a agir na direção de um horizonte de conscientização; tomada de atitudes para mudança da realidade em termos qualitativos. Por consequência, espera-se influenciar as autoridades a compreenderem que tanto a APA, quanto a população e o ambiente vivido podem ser melhorados e zelados com execução de políticas públicas consistentes e contínuas.

\section{REFERÊNCIAS}

AGUIAR, Josiane do Socorro et al. Caracterização e Avaliação das Condições de Vida das Populações Residentes nas Ressacas Urbanas dos Municípios de Macapá e Santana. pp.165236. In: Takiyama, L.R.; Silva, A.Q. da (orgs.). Diagnóstico das Ressacas do Estado do Amapá: Bacias do Igarapé da Fortaleza e Rio Curiaú, Macapá-AP, CPAQ/IEPA e DGEO/SEMA, 2003, p. 165-230.

ALVES, H. P. F. Vulnerabilidade socioambiental na metrópole paulistana: uma análise sociodemográfica das situações de sobreposição espacial de problemas e riscos sociais e ambientais. São Paulo: Revista Brasileira de Estudos de População, v. 23, n. ${ }^{\circ}$ 1, jan./jun. 2006. p. 43-59.

AMAPÁ. Secretaria de Estado do Meio Ambiente, Áreas protegidas do Estado do Amapá. / Coordenação Geoprocessamento e Tecnologia da Informação Ambiental - CGTIA: Macapá, 2012.

BARDIN, Laurence. Análise de Conteúdo. São Paulo: Edições 70, 2011. 
BONETI, Lindomar Wessler. Políticas públicas por dentro. Ijuí: Unijuí, 2006.

BRASIL. Constituição da República Federativa do Brasil, promulgada em 5 de outubro de 1988. Brasília: Congresso Nacional, 1988.

CARVALHO, Isabel Cristina de Moura. Educação ambiental: a formação do sujeito ecológico. 6 ed. São Paulo: Cortez, 2012.

COUTO, Hildo Honório do. Ecolinguística: estudo das relações entre língua e meio ambiente. Brasília: Thesaurus, 2007.

2009.

Linguística, ecologia e ecolinguística: contato de línguas. São Paulo: Contexto,

COUTO, Elza Kioko Nakayama Nenoki do et al (orgs.). Linguística Ecossistêmica: 10 anos de Ecolinguística no Brasil. Campinas, SP: Pontes Editores, 2017.

COUTO, Elza Kioko Nakayama Nenoki do. Análise do discurso ecológica: fundamentação teórico-metodológica. Revista de Estudos da Linguagem, Belo Horizonte, v. 23, n.2, p. 485$509,2015$.

; FERNANDES, Eliana Marquez da Fonseca. Aquisição de língua: uma perspectiva Ecolinguística. Letras de Hoje, Porto Alegre, v. 48, n. 3, p. 290-298, jul./set. 2013.

; COUTO, Hildo Honório do. Ecolinguística, linguística ecossistêmica e análise do discurso ecológica (ADE). Disponível em:

$<$ https://www.researchgate.net/publication/311917846_Ecolinguistica_linguistica_ecossistemi ca_e_analise_do_discurso_ecologica_ADE>. Acesso em: 02 out. 2017.

CUNHA, Alan Cavalcanti da et al. Estudo preliminar sobre a variação espaço-temporal de parâmetros de qualidade de água no Igarapé da Fortaleza. In: TAKIYAMA, L. R.; SILVA, A. Q. (Orgs.). Diagnóstico das ressacas do estado do Amapá: bacias do Igarapé da Fortaleza e Rio Curiaú. Macapá: CPAQ, IEPA/DGEO, SEMA, 2003. p. 105-136.

FIGUEIRA, Sérgio Sampaio. Percepções Socioambientais narradas pelos habitantes do aglomerado subnormal do Igarapé da Fortaleza-AP. 2013. 123f. Dissertação (mestrado) Universidade Federal do Amapá, Programa de Pós-Graduação em Direito Ambiental e Políticas Públicas. Macapá, 2013.

FIGUEIREDO, João B. A. Educação Ambiental Dialógica: as contribuições de Paulo Freire e a cultura sertaneja nordestina. Fortaleza: Edições UFC, 2007.

FREIRE, Paulo. Educação e mudança. 3 ed. São Paulo: Paz e Terra, 1981.

GIL, Antônio Carlos. Métodos e técnicas de pesquisa social. $6^{\text {a }}$ Ed. São Paulo: Atlas, 2008.

IBGE. Censo demográfico 2010 - resultado do universo. Rio de Janeiro, 2011. 1 CD ROM. 
LEFEBVRE, Henri. O Direito à Cidade. (1968). Tradução de Rubens Eduardo Farias. São Paulo: Centauro, 2001, $4^{\text {a }}$ ed. 2006.

LESTINGE, Roberto. Belo Monte: um estudo crítico-discursivo e ecolinguístico de notícias veiculadas no Jornal Nacional. 2013. 379 f. Tese (Doutorado em Filologia e Língua Portuguesa) - programa de Pós-Graduação, Universidade de São Paulo, São Paulo, 2013.

MARICATO, Ermínia. Brasil, Cidades: Alternativas para a crise urbana. Petrópolis-RJ: Vozes, 2001.

MINAYO, Maria Cecília de Souza (org.). Pesquisa social: teoria, método e criatividade. Petrópolis-RJ: Vozes, 2002.

PERNAMBUCO, Marta Maria; SILVA, Antônio Fernando G. da. Paulo Freire: a educação e a transformação do mundo. In: Pensar o ambiente: bases filosóficas para a Educação Ambiental. Isabel Cristina de Moura Carvalho, Mauro Grün e Rachel Trajber (org.). Edição eletrônica. Brasília: Ministério da Educação, Secretaria de Educação Continuada, Alfabetização e Diversidade, UNESCO, 2006. p. 207-219.

PORTILHO, Ivone dos Santos. Áreas de ressaca e dinâmica urbana em Macapá/AP. Disponível em: <http://www.uc.pt/fluc/cegot/VISLAGF/actas/tema4/ivone>. Acesso em: 26 jul. 2017.

REIGOTA, Marcos. A floresta e a escola: por uma educação ambiental pós-moderna. São Paulo: Cortez, 2002.

SANTOS, E.R.C. Amazônia Setentrional Amapaense: do "mundo" das águas às florestas protegidas. Presidente Prudente, 2012. 276 p. Tese (doutorado) - Faculdade de Ciências e Tecnologia, Universidade Estadual Paulista.

SARMENTO, Manoel Soares. Meio ambiente e linguagem - por uma ecolexicografia.

Confluências - Revista de Tradução Científica e Técnica, no 0, Maio de 2004, pp. 119-130. Disponível em: < http://meioambienteelinguagem.blogspot.com.br/2012/02/por-umaecolexicografia.html>. Acesso em: 10 jul. 2017.

SILVA, Veridiana Mazon Barbosa da. Ecolinguística: uma perspectiva entre Linguagem, Discurso, Educação e Meio Ambiente. Enciclopédia Biosfera, Centro Científico Conhecer Goiânia, vol. 6, n.10, 2010.

TAKIYAMA, Luís Roberto et al. Qualidade das Águas das Ressacas das Bacias do Igarapé da Fortaleza e do Rio Curiaú. In: Takiyama, L.R.; Silva, A.Q. da (orgs.). Diagnóstico das

Ressacas do Estado do Amapá: Bacias do Igarapé da Fortaleza e Rio Curiaú, Macapá-AP, CPAQ/IEPA e DGEO/SEMA, 2003, p. 81-104.

TORRES, H. A demografia do risco ambiental. In: TORRES, H.; COSTA, H. (Orgs.). População e meio ambiente: debates e desafios. São Paulo: Editora SENAC, 2000. p. 53-73 


\section{$\underline{\text { SOBRE OS AUTORES }}$}

\section{Marcelo Conceição da Rocha Campos}

Mestrando em Educação pelo Programa de Pós-Graduação em Educação da Universidade Federal do Amapá (UNIFAP); Licenciado em Letras pela mesma instituição, advogado, professor da rede estadual de ensino; Amapá-Brasil. E-mail: mcrcap@ bol.com.br http://orcid.org/0000-0001-7801-7038

\section{Eliana do Socorro de Brito Paixão}

Doutora em Educação pela UFU/MG; Professora efetiva da Universidade Federal do Amapá (UNIFAP), vinculada ao Programa de Pós-Graduação em Educação/UNIFAP como professora permanente e ao curso de Graduação em Tecnologia em Secretariado; AmapáBrasil. E-mail: elianapaixao@ unifap.br

http://orcid.org/000.0002.7978.1836

Recebido em: 25 de fevereiro de 2019 Aprovado em: 29 de abril 2019

Publicado em: 01 de julho de 2019 